\title{
Relationships between Secondary School Students' Perceptions of School Adjustment and Well-being
}

\author{
Su-ching Lin (Corresponding author) \\ Graduate Institute of Education, National Changhua University of Education, Taiwan \\ 1, Jin De Road, Paisha Village, Changhua City, Changhua County 500, Taiwan \\ E-mail: sclin@cc.ncue.edu.tw \\ Chun-Tsu Hsu \\ YunLin county Linnei Township Yuan Ming Junior High School \\ 3, Park Road, Linnei Township, Yunlin County \\ E-mail:t885852@yahoo.com.tw
}

The research is financed by the Ministry of Science and Technology, Taiwan. No. MOST 108-2410-H-018016-MY2

Abstract

Both school adjustment and well-being are fundamental to a good quality of life for youth. Good school adjustment is important and has far-reaching influences on the psychology and behavior of middle school students, which sets the stage for future educational and occupational opportunities. Good mental health or well-being helps young people develop the skills they need to cope with whatever life throws at them. The purposes of this study were to explore the relationships between secondary school students' perceptions of school adjustment and well-being. 890 secondary students were selected from central Taiwan. A questionnaire was applied to collect data. Data were analyzed by using descriptive statistics, one-way ANOVA, Pearson's product-moment correlation, and multiple regression analysis. The findings of this study were as follows: First, students' perceptions of school adjustment and well-being were moderate level. Second, respondents with different family socio-economic status showed significant differences in school adjustment including dimensions of overall, academic adjustment, proper behavior, and self-affirmation, and also showed significant differences in well-being including dimensions of overall, life satisfaction, physical-mental health, and self-evaluation. Third, there was a medium positive correlation between respondents' school adjustment and well-being. The school adjustment could predict well-being and the peer relationship and the self-assurance were the better predictors of well-being.

Keywords: Secondary school students, School adjustment, Well-being

DOI: $10.7176 / \mathrm{JEP} / 11-30-19$

Publication date:October $31^{\text {st }} 2020$

\section{Introduction}

Adolescence is the period of transition between childhood and adulthood. It includes some big changes- to the body, and to the way a young person relates to the world (Virtanen, Vasalampi, Torppa, Lerkkanen, \& Nurmic, 2019). Schools are an important environment of socialization and learning for adolescents. Adolescents spend more waking time in school than in any other context (Eccles \& Roeser, 2011). In school. they invest a good part of their daily time, interacting with teachers and colleagues and participating in activities, which promote cognition, and social and emotional development. They are also expected to get to and from classes on their own, manage time wisely, organize and keep up with materials for multiple classes, be responsible for all classwork and homework from multiple teachers, and at the same time develop and maintain a social life (Meece \& Eccles, 2010). However, when they transition from elementary to middle school, many students are undergoing physical, intellectual, social, emotional, and moral changes during this time can bring anticipation and anxiety for both children and their families (Allen \& Waterman, 2019; Parker, 2013). School adjustment is important and has farreaching influences on the psychology and behavior of middle school students because school adjustment sets the stage for future educational and occupational opportunities. The most serious consequence of school failure, particularly dropping out of school, is the high risk of unemployment or underemployment in adulthood that 
follows. In contrast, good school adjustment can set the stage for college or future vocational training and opportunities.

School adjustment refers to the student's academic skills to adapt to maintain a good relationship with teachers and peers (Arkoff,1968). Youngaman (1979) indicated that students' school adjustment could be measured from three dimensions, such as learning adaptation, discipline adaptation, and the teacher-student relationship. Perry and Weinstein (1998) submitted that The connotation of school adjustment could be divided into three parts: (1) academic skills and motivations, which refer to students' achievements in skills, multiple cognitive skills, school values, learning objectives, post-cognitive, academic performance, and ability-related beliefs. (2) social function refers to the relationship with school peers and teachers, such as a sense of belonging, acceptance by peers, quality of friendship, social goals. (3) behavioral function refers to the behavioral rules that students can abide by in their own role, and can delay satisfaction, control impulsive behavior, and concentration in the self-regulation of attention and emotion. In short, good school adjustment includes academic adaptation, good teacher-student relationships, peer relationships, proper behavior, and self-affirmation.

Mental well-being is fundamental to a good quality of life. Happy and confident children are most likely to grow into happy and confident adults, who in turn contribute to the health and well-being of nations (Rao, 2001). Therefore. well-being is just as important as physical health. Good mental health or well-being helps young people develop the skills they need to cope with whatever life throws at them. In recent years, the way mental health is assessed often takes well-being as an important research indicator, because people with better well-being usually maintain a healthier state of mind. However, well-being is a comprehensive assessment of the satisfaction, positive, and negative emotions felt by individuals in their lives, based on their subjective experience (Andrews \&Withey, 1976). Olweus (1991) indicated that well-being in young people has implications for self-esteem, behavior, attendance at school, educational achievement, social cohesion, and future health and life chances. In other words, people who often experience well-being usually have more friends and more social support, more opportunities for social interaction, more productive, a better quality of work, and enough energy to meet all kinds of challenges in life. However, school education pays more attention to teaching and learning, pays more attention to students' cognitive development and academic achievement, but pays less attention to the subjective evaluation of students' life satisfaction, positive emotion, and negative emotion.

Taiwan has been implemented 12 years of basic education reform since 2019, no matter of the teaching methods, curriculum content, learning assessment approaches, and entrance examination are significantly different from before, secondary school students must re-adapt to this wave of educational reform and preparation for the examination, their perceptions of school adjustment and well-being should be concerned and understood, so this study investigates the circumstances of school adjustment and well-being of Taiwanese secondary school students. Moreover, the different family socio-economic status may influence students' perceptions of school adjustment and well-being, which is worth explored further. Several studies conducted in Taiwan explored that there was a positive correlation, and school adjustment could predict well-being (Gu, 2014; Lin, 2004; Tan, 2013). However, with the 12 years of basic education reform, the researchers want to investigate the relationship between secondary school students' perceptions of school adjustment and well-being again to understand whether or not their relationship has been changed. Therefore, the research questions are discussed in this study include: 1) what are the current situations of secondary school students' perceptions of school adjustment and well-being? 2) Do it exist different in school adjustment and well-being among students with different family socio-economic status? 3)What is the relationship between school adjustment and well-being of secondary school students? 4) Could the perception of school adjustment predict well-being?

\section{Methodology}

\subsection{Participants}

Nine hundred junior high school students selected from central Taiwan were selected to complete the questionnaires of School adjustment and Well-being. To ensure confidentiality, each questionnaire was completed anonymously. With a response rate of $99.11 \%, 892$ students returned completed questionnaires. The total number of valid questionnaires was 890 , with a valid questionnaire rate of $99.78 \%$, so the number of valid samples in this study was 890 consisting of $50.90 \%$ male $(n=453), 49.10 \%$ female $(n=437)$. On the distribution of family social economic status (SES), students from low SES was 49.60\% $(n=442)$, middle SES was $24.30 \%(n=216)$, high SES was $26.1 \%(\mathrm{n}=232)$. 


\subsection{Instruments}

Two instruments were used in this study. One was the School Adjustment Questionnaire (SAQ) developed by Lin (2004) was administered to measure how junior high school students perceived school experience referring to the degree to which students' behavior and environment were balanced and harmonious in the school environment by using 29 items in five dimensions, namely, academic adaptation (5 items), teacher-student relationship (4 items), peer relationship (4 items), proper behavior ( 8 items), and self-affirmation ( 8 items). The student responded to the items on a five-point Likert scale, ranging from 1 for "strong unconformity" to 5 for "strong conformity." The factor analysis made on data obtained by SAQ in the current application reveals that the factor load of each subject item of the school adjustment questionnaire is greater than .45 , the value of each dimensional characteristic is between 2.18 and 4.17 , and the cumulative total variation is $52.27 \%$, indicating good validity of the items within this questionnaire. The overall internal consistency (Cronbach's $\alpha=.90$ ) for the scale in the current sample was good. The Cronbach's $\alpha$ for the five subscales ranged from .67 to .83 , indicating good internal consistencies of the items within each subscale.

Another instrument is the Well-being Questionnaire (WBQ) developed by Lin (2004) was administered to measure how junior high school students perceived the satisfaction of an individual life by using 23 items in four dimensions, namely, life satisfaction (9 items), positive and negative emotions (4 items), physical and mental health (6 items), and self-esteem (4 items). The student responded to the items on a five-point Likert scale, ranging from 1 for "strong unconformity" to 5 for "strong conformity". The respondents were checked according to the actual perception. The factor analysis made on data obtained by WBQ in the current application reveals that the factor load of each subject item of the well-being questionnaire is greater than .45 , the value of each dimensional characteristic is between 2.05 and 3.75, and the cumulative total variation is $49.30 \%$, indicating good validity of the items within this questionnaire. The overall internal consistency (Cronbach's $\alpha=.87$ ) for the scale in the current sample was good. The Cronbach's $\alpha$ for the five subscales ranged from .66 to .82 , indicating good internal consistencies of the items within each subscale.

\section{Results}

3.1 Secondary students' perceptions of school adjustment and well-being circumstances

Table 1 and Table 2 indicated that students' perceptions of school adjustment and well-being were moderate level.

Table 1. students' perception of school adjustment circumstance

\begin{tabular}{lcc}
\hline \multicolumn{1}{c}{$S A Q$} & $\mathrm{M}$ & $\mathrm{SD}$ \\
\hline academic adaptation & 3.29 & 0.74 \\
teacher-student relationship & 3.29 & 0.70 \\
peer relationship & 3.75 & 0.73 \\
proper behavior & 3.75 & 0.65 \\
self-affirmation & 3.15 & 0.55 \\
overall & 3.44 & 0.49 \\
\hline
\end{tabular}

$n=890$

Table 2. students' perception of well-being circumstance

\begin{tabular}{lcc}
\hline WBQ Dimension & M & SD \\
\hline life satisfaction & 3.67 & 0.69 \\
positive and negative emotions & 3.12 & 0.79 \\
physical and mental health & 3.46 & 0.71 \\
self-esteem & 3.00 & 0.70 \\
overall & 3.40 & 0.57 \\
\hline
\end{tabular}

$n=890$

\subsection{Difference analyses in SES on students' perceived school adjustment and well-being}

Table 3 showed the mean and standard deviation of SAQ in different levels of SES. Table 4 showed difference analysis results, which indicated that significant differences among low, middle, and high SES in the three dimensions consisting of academic adaptation $(\mathrm{F}=11.99, \mathrm{p}<.001)$, self-affirmation $(\mathrm{F}=8.07, \mathrm{p}<.001)$, and overall $(\mathrm{F}=9.28, \mathrm{p}<.001)$. Scheffé tests revealed that students with high SES had higher scores than students with 
low and middle SES in these three dimensions. Also, there was a significant difference in the dimension of proper behavior $(\mathrm{F}=4.17, \mathrm{p}<.05)$. Scheffé tests revealed that students with high SES had higher scores than the students with low SES in this dimension.

Table 3 Summary of mean scores and standard deviations of SAQ in SES

\begin{tabular}{|c|c|c|c|c|c|c|}
\hline \multirow{3}{*}{ Dimension } & \multicolumn{4}{|c|}{ SES } & \multirow{2}{*}{\multicolumn{2}{|c|}{ High $(\mathrm{n}=232)$}} \\
\hline & \multicolumn{2}{|c|}{$\operatorname{low}(n=442)$} & \multicolumn{2}{|c|}{ middle $(n=216)$} & & \\
\hline & $\bar{M}$ & SD & $\mathrm{M}$ & SD & $\mathrm{M}$ & SD \\
\hline academic adaptation & 3.19 & .72 & 3.28 & .72 & 3.48 & .76 \\
\hline teacher-student relationship & 3.27 & .68 & 3.25 & .73 & 3.38 & .71 \\
\hline peer relationship & 3.71 & .70 & 3.75 & .77 & 3.83 & .76 \\
\hline proper behavior & 3.69 & .61 & 3.77 & .65 & 3.84 & .69 \\
\hline self-affirmation & 3.10 & .54 & 3.14 & .49 & 3.27 & .59 \\
\hline overall & 3.39 & .48 & 3.44 & .49 & 3.56 & .52 \\
\hline
\end{tabular}

Table 4 Summary of one-way ANOVA analysis of SAQ in different SES

\begin{tabular}{|c|c|c|c|c|c|}
\hline Source & SS & df & MS & $F$ value & Scheffé \\
\hline \multicolumn{6}{|l|}{ academic adaptation } \\
\hline Between groups & 12.73 & 2 & 6.37 & $11.99^{* * *}$ & $3>1,2$ \\
\hline Within groups & 470.98 & 887 & .53 & & \\
\hline total & 483.71 & 889 & & & \\
\hline \multicolumn{6}{|l|}{ teacher-student relationship } \\
\hline Between groups & 2.50 & 2 & 1.25 & 2.56 & \\
\hline Within groups & 433.63 & 887 & .49 & & \\
\hline total & 436.13 & 889 & & & \\
\hline \multicolumn{6}{|l|}{ peer relationship } \\
\hline Between groups & 2.14 & 2 & 1.07 & 2.00 & \\
\hline Within groups & 476.66 & 887 & .54 & & \\
\hline total & 478.80 & 889 & & & \\
\hline \multicolumn{6}{|l|}{ proper behavior } \\
\hline Between groups & 3.48 & 2 & 1.74 & $4.17^{*}$ & $3>1$ \\
\hline Within groups & 370.27 & 887 & .42 & & \\
\hline total & 373.75 & 889 & & & \\
\hline \multicolumn{6}{|l|}{ self-affirmation } \\
\hline Between groups & 4.73 & 2 & 2.36 & $8.07^{* * *}$ & $3>1,2$ \\
\hline Within groups & 260.02 & 887 & .29 & & \\
\hline total & 264.75 & 889 & & & \\
\hline \multicolumn{6}{|l|}{ overall } \\
\hline Between groups & 4.46 & 2 & 2.23 & $9.28^{* * *}$ & $3>1,2$ \\
\hline Within groups & 213.21 & 887 & .24 & & \\
\hline total & 217.68 & 889 & & & \\
\hline
\end{tabular}

$n=890,{ }^{*} p<.05 .{ }^{* * *} p<.001$.

Note: $1=$ low SES; $2=$ middle SES; $3=$ high SES

Table 5 showed the mean and standard deviation of WBQ in different levels of SES. Table 6 showed difference analysis results, which indicated that significant differences among low, middle, and high SES in the four dimensions including life satisfaction $(\mathrm{F}=3.85, \mathrm{p}<.05)$, physical and mental health $(\mathrm{F}=4.35, \mathrm{p}<.05)$, self-esteem $(\mathrm{F}=4.46, \mathrm{p}<.05)$, and overall $(\mathrm{F}=5.30, \mathrm{p}<.01)$. Scheffé tests revealed that students with high SES had higher scores than students with low SES in these dimensions. 
Table 5 Summary of analysis of the WBQ in different SES

\begin{tabular}{|c|c|c|c|c|c|c|}
\hline \multirow{3}{*}{ Dimension } & \multicolumn{4}{|c|}{$\underline{\text { SES }}$} & \multirow{2}{*}{\multicolumn{2}{|c|}{ High $(\mathrm{n}=232)$}} \\
\hline & \multicolumn{2}{|c|}{$\operatorname{low}(n=442)$} & \multicolumn{2}{|c|}{ middle $(n=216)$} & & \\
\hline & $\mathrm{M}$ & $\overline{\mathrm{SD}}$ & $\mathrm{M}$ & SD & $\mathrm{M}$ & SD \\
\hline life satisfaction & 3.19 & .72 & 3.28 & .72 & 3.48 & .76 \\
\hline positive and negative emotions & 3.27 & .68 & 3.25 & .73 & 3.38 & .71 \\
\hline physical and mental health & 3.71 & .70 & 3.75 & .77 & 3.83 & .76 \\
\hline self-esteem & 3.69 & .61 & 3.77 & .65 & 3.84 & .69 \\
\hline overall & 3.39 & .48 & 3.44 & .49 & 3.56 & .52 \\
\hline
\end{tabular}

$n=890$.

Table 6 Summary of analysis of the WBQ in different SES

\begin{tabular}{|c|c|c|c|c|c|}
\hline Source & SS & df & MS & F value & Scheffé \\
\hline \multicolumn{6}{|l|}{ life satisfaction } \\
\hline Between groups & 3.69 & 2 & 1.85 & $3.85^{*}$ & $3>1$ \\
\hline Within groups & 424.91 & 887 & .48 & & \\
\hline total & 428.60 & 889 & & & \\
\hline \multicolumn{6}{|l|}{ positive and negative emotions } \\
\hline Between groups & 2.04 & 2 & 1.02 & 1.62 & \\
\hline Within groups & 559.35 & 887 & .63 & & \\
\hline total & 561.39 & 889 & & & \\
\hline \multicolumn{6}{|l|}{ physical and mental health } \\
\hline Between groups & 4.33 & 2 & 2.16 & $4.35^{*}$ & $3>1$ \\
\hline Within groups & 441.15 & 887 & .50 & & \\
\hline total & 445.48 & 889 & & & \\
\hline \multicolumn{6}{|l|}{ self-esteem } \\
\hline Between groups & 4.36 & 2 & 2.18 & $4.46^{*}$ & $3>1$ \\
\hline Within groups & 433.70 & 887 & .49 & & \\
\hline total & 438.06 & 889 & & & \\
\hline \multicolumn{6}{|l|}{ overall } \\
\hline Between groups & 3.38 & 2 & 1.69 & $5.30^{* *}$ & $3>1$ \\
\hline Within groups & 282.65 & 887 & .32 & & \\
\hline total & 286.03 & 889 & & & \\
\hline total & 217.68 & 889 & & & \\
\hline
\end{tabular}

$N=890,{ }^{*} p<.05 .{ }^{* * *} p<.001$.

note: $1=$ low SES; $2=$ middle SES; $3=$ high SES

\subsection{The correlation between students 'perceived school adjustment and well-being}

Table 7 showed the inter-correlations among SAQ and WBQ. The five SAQ subscales and four WBQ subscales significantly correlated with each other. At the academic adaptation level, the highest correlation was overall ( $\mathrm{r}=.46$, $\mathrm{p}<.001)$. At the teacher-student relationship level, the highest correlation was life satisfaction $(\mathrm{r}=.45, \mathrm{p}<.001)$. At the peer relationship level, the highest correlation was life satisfaction $(r=.68, p<.001)$. At the proper behavior level, the highest correlation was overall $(\mathrm{r}=.46, \mathrm{p}<.001)$. At the self-affirmation level, the highest correlation was self-esteem $(r=.67, \mathrm{p}<.001)$. At the overall level, the highest correlation was overall $(\mathrm{r}=.69, \mathrm{p}<.001)$. 
Table 7 Summary of correlation analysis between SAQ and WBQ

\begin{tabular}{lccccc}
\hline Dimension & LS & PNE & PMH & SE & OA \\
\hline academic adaptation & $.39^{* * *}$ & $.20^{* * *}$ & $.45^{* * *}$ & $.39^{* * *}$ & $.46^{* * *}$ \\
teacher-student relationship & $.45^{* * *}$ & $.29^{* * *}$ & $.32^{* * *}$ & $.19^{* * *}$ & $.43^{* * *}$ \\
peer relationship & $.68^{* * *}$ & $.50^{* * *}$ & $.48^{* * *}$ & $.33^{* * *}$ & $.67^{* * *}$ \\
proper behavior & $.44^{* * *}$ & $.21^{* * *}$ & $.44^{* * *}$ & $.26^{* * *}$ & $.46^{* * *}$ \\
self-affirmation & $.45^{* * *}$ & $.32^{* * *}$ & $.52^{* * *}$ & $.67^{* * *}$ & $.61^{* * *}$ \\
overall & $.62^{* * *}$ & $.39^{* * *}$ & $.59^{* * *}$ & $.51^{* * *}$ & $.69^{* * *}$ \\
\hline
\end{tabular}

${ }^{* * *} p<.001$

note: $L S=$ life satisfaction; $P N E=$ positive and negative emotions; $P M H=$ physical and mental health; $S E=s e l f$ evaluation; $O A=$ overall

\subsection{The prediction of Well-being from school adjustment}

Multiple regression analyses were also performed to take advantage of our large sample size $(\mathrm{n}=890)$. Each of the multiple regression analyses performed had a WB measure as the dependent measure. Predictor variables included scores of academic adaptation, teacher-student relationship, peer relationship, proper behavior, selfaffirmation. Table 8 indicated $\mathrm{F}(5,884)=265.90$, $\mathrm{p}$-value $<.001$, and $\mathrm{R}=.78$, the $\mathrm{R} 2=.60$. That is, SA could explain $60 \%$ of the variance in perceived WB. Further, three predictor variables, peer relationship $(\mathrm{t}(884)=18.79, \beta=.47$, $\mathrm{p}<.001)$, proper behavior $(\mathrm{t}(884)=3.58, \beta=.10, \mathrm{p}<.001)$; and self-affirmation, $(\mathrm{t}(884)=11.16, \beta=.31, \mathrm{p}$ $<.001)$ could significantly predict students' WB. The peer relationship was the best predictor.

Table 8 Summary of the multiple regression analysis of school adaptation to overall well-being

\begin{tabular}{|c|c|c|c|c|}
\hline \multicolumn{2}{|c|}{ criterion variables } & \multicolumn{2}{|l|}{ WBQ } & \multirow[b]{2}{*}{$t$} \\
\hline predictor variables & $\mathrm{B}$ & $\mathrm{SE}_{\mathrm{B}}$ & $\beta$ & \\
\hline academic adaptation & .05 & .02 & .06 & 1.90 \\
\hline $\begin{array}{l}\text { teacher-student } \\
\text { relationship }\end{array}$ & .04 & .02 & .05 & 1.89 \\
\hline peer relationship & .36 & .02 & .47 & $18.79^{* * *}$ \\
\hline proper behavior & .09 & .03 & .10 & $3.58^{* * *}$ \\
\hline self-affirmation & .32 & .03 & .31 & $11.16^{* * *}$ \\
\hline$F(5,884)$ & \multicolumn{3}{|c|}{$265.90^{* * *}$} & \\
\hline$R$ & \multicolumn{3}{|c|}{.78} & \\
\hline$R^{2}$ & \multicolumn{3}{|c|}{.60} & \\
\hline Adj. $R^{2}$ & \multicolumn{3}{|c|}{.60} & \\
\hline
\end{tabular}

\section{Conclusion and Discussion}

The purposes of this study were to explore the relationships between secondary school students' perceptions of school adjustment and well-being. Participants were 890 seventh to ninth graders selected from central Taiwan. The findings of this study were as follows:

First, students' perceptions of school adjustment and well-being were moderate level. The result is similar to the studies conducted by Gu (2014), Lin (2004), and Tan (2013), it shows that secondary school students' perceptions of school adaptation and well-being in Taiwan have not changed with the 12-year national education reform. Such results may be related to the measuring tool. School-adjustment Scale includes the dimensions of academic adaptation, good teacher-student relationship, peer relationship, proper behavior, and self-affirmation. These dimensions must be taught regardless of educational reform. Further, the impact sources of well-being are complex, and educational reform may not have a significant impact on student awareness in life satisfaction, positive and negative emotions, physical and mental health, and self-esteem.

Second, students with different family SES showed significant differences in overall school adjustment and dimensions of academic adjustment, proper behavior, and self-affirmation. The result indicated that high family SES students' perceptions of school adjustment were better than that of low family SES students. The result is 
similar to the study conducted by Gu (2014). The possible reason for this result is that parents with higher SES pay more attention to and invest more resources in their children's learning and behavior.

Third, participants with different family SES showed significant differences in overall well-being and dimensions of life satisfaction, physical-mental health, and self-evaluation. The result indicated that high family SES students' perceptions of well-being were better than that of low family SES students. The possible reasons for this result, high family SES of students have more economic and social resources. Their parents are more concerned about their children's health, pay more time to accompany children, as far as possible for children to arrange a variety of learning activities, so that students from high family SES in life satisfaction, physical and mental health, and selfevaluation are better than low family SES students.

Fourth, there was a medium positive correlation between students' perceptions of school adjustment and wellbeing. The school adjustment could predict well-being. Of school adjustment, the dimensions of the peer relationship and the self-assurance were the better predictors of well-being. The result is similar to the studies conducted by $\mathrm{Gu}$ (2014) and Lin (2004). The possible reasons for these results, peer affiliation, and peer support are highly valued at the youth age. Good peer relations are conducive to the healthy development of young people's self-concept and personality. Those who have a positive self-concept, have confidence in themselves, and believe that they are capable, produce better self-evaluation, self-esteem, which will affect the mental health and life satisfaction of young people. Rogers (1951) pointed out that people who present self-affirmation are often able to express their needs, opinions, feelings, and beliefs in a direct, sincere, and appropriate manner, as well as to respect others. Students with good self-concepts are usually more likely to perform their strengths, overcome their shortcomings, have a certain degree of understanding of their own abilities and future career directions. In general, they are more confident in all aspects of their performances, with a higher sense of self-worth, while also being able to appreciate the advantages of others in the same way. Some future research suggestions in this study include the following. First, add the research samples selected from different regions, especially in other countries to understand the differences between different samples and different regions, so that the results of the study more representative and inferred. Second, step-by-step regression analysis can be used in the analysis of predictive forces to exclude collinearity. Moreover, add qualitative methods such as interviews or observation to obtain more abundant information and learn more about the factors contributing to the results of the survey. The researcher believes using a mixed-method to collect data will make the study can be more reliable.

\section{References}

Allen, B. \& Waterman, H. (2019). Stages of Adolescence. Retrieved from https://www.healthychildren.org/English/ages-stages/teen/Pages/Stages-of-Adolescence.aspx

Andrews, F. M., \& Withey, S. B. (1976). Social indicators of well-being. New York: Plenum.

Arkoff, A. (1968). Adjustment and mental health. New York: McGraw-Hill.

Eccles, J. S., \& Roeser, R. W. (2011). Schools as developmental contexts during adolescence. Journal of Research on Adolescence, 21(1), 225-241.

Gu, J. P. (2014). Study on the relationship between adaptation and well-being of May-May Junior High School students in Hsinchu County (unpublished master's thesis). National Taichung Education University, Taichung, Taiwan.

Lin, W. C. (2004). Study on family function, school adjustment, and well-being of middle school students (unpublished master's thesis). National Changhua University of Education, Changhua County.

Meece, J. L. \& Eccles, J. S. (Eds.). (2010). Handbook on research on schools, schooling, and human development. New York, NY: Routledge.

Olweus, D. (1991). Bully victim problems among school children: some basic facts and effects of a school based intervention program. In D. Pepler \& K, Rubin (eds). The development and treatment of childhood aggression (pp.411-418). Hillsdale, NJ, Erbaum.

Parker, A. K. (2013). Understanding and supporting young adolescents during the transition into middle school. In P. G. Andrews (Ed.), Research to guide practice in middle grades education (pp. 495-510). Westerville, $\mathrm{OH}$ : Association for Middle Level Education.

Perry, K. E., \& Weinstein, R. S. (1998). The social context of early schooling and children's school adjustment. Educational Psychologist, 33, 177-194. 
Rao, M. (2001). Promoting children's emotional well-being: a book review. Journal of Public Health Medicine, 23(2), 168.

Rogers, C. R. (1951). Client-Centered Therapy. Boston: Houghton Mifflin.

Tan, S. Y. (2013). Research on the relationship among peer affiliation, school adjustment, and well-being of middle school students (unpublished master's thesis). National Changhua University of Education, Changhua County.

Virtanen, T. E., Vasalampi, K., Torppa, M., Lerkkanen, M. -K., \& Nurmic, J. -E. (2019). Changes in students' psychological well-being during transition from primary school to lower secondary school: A personcentered approach. Learning and Individual Differences, 69, 138-149.

Youngman, M. B. (1979). Assessing behavioral adjustment to school. British Journal of Educational Psychology, 49, 258-264. 